\title{
A Tribute to Professor James Lauer
}

It was with great sadness that we learned of Professor James Lauer's passing on 16th November 2008. James Lauer was born in Vienna in 1920 and completed his high school studies in Vienna. In 1938, he and his family emigrated to the United States. After completing his college studies, he started work at Sun Oil Company, which decided to send him to the University of Pennsylvania to study for his Ph.D. in Physics, which he completed in a record-breaking 2.5 years. In 1977, when Sun Oil changed ownership, he moved to Rensselaer Polytechnic Institute to begin an academic career where he rapidly became one of their most productive researchers and most stimulating teachers. During this period, he wrote over 150 papers and filed more than 30 patents. He performed pioneering work in areas such as sulfur removal, the measurement of pressure-dependent lubricant viscosities, the study of the role of carbon as a tribological interface, and the development of spectroscopic methods for understanding lubricant decomposition.

In 1993, Professor Lauer moved to San Diego, working as an Emeritus Professor at the Center for Magnetic
Recording Research at the University of California, San Diego. In the early years following his move to San Diego, he was actively involved in spectroscopic studies of carbon-coated hard disks and other tribological problems encountered in the computer industry. He was respected and admired for his contributions to the improved understanding of the tribology of magnetic tapes and disks and for his unselfish commitment to helping in the education of the next generation of tribologists.

It was during this time that the fledgling journal, Tribology Letters, asked him if he would become a member of its Editorial Board. He graciously agreed and his diligent reviewing and quiet and considered advice helped us in those early years to grow and flourish. In addition to being an outstanding scientist, he was always a true gentleman with a dry and charming sense of humor. He will be deeply missed not only as an insightful and creative scientist but also as a good friend and gentle human being.

Frank Talke, Nic Spencer, and Eddy Tysoe 